\title{
EL PENSAMIENTO ESTETICO DE SAMUEL RAMOS
}

P O R

\author{
JUSTINO FER N A N D Z
}

P ARA darnos cuenta del pensamiento estético de Samuel Ramos $P$ tenemos, por una parte, un grupo de ensayos y artículos, publicados a lo largo de su vida y que han sido agrupados en un cierto orden -según el índice que se incluye aquí al final- por los profesores Juan Hernández Luna y Rafael Moreno, como preparación de un volumen que ha de ser publicado próximamente bajo el título de: Estudios de Estética. 1 Por otra parte contamos con su libro: Filosofia de la vida artística, $^{2}$ en el que resumió y organizó prácticamente todas sus ideas y su actitud respecto de la Estética.

Ahora bien, con objeto de presentar el pensamiento estético de Ramos, o bien su doctrina estética, en la forma más clara, he procedido de la siguiente manera:

a) He agrupado las ideas, recogidas tras la lectura de sus Estudios de Estética, por temas, dándoles un orden en cierta medida sistemático.

- Ponencia presentada en la Mesa Redonda que tuvo lugar el 9 de octubre de 1959 en la Universidad Nacional Autónoma de México, con el tema: la doctrina estética de Samuel Ramos.

1 El volumen en preparación será publicado por el Instituto de Investigaciones Estéticas, de la Universidad Nacional Autónoma de México, en su serie de: "Estudios de Arte y Estética."

2 Ramos, Samuel. Filasofta de la vida artística. Buenos Aires-México, EspasaCalpe Argentina, S. A. 1950. (Colección Austral, núm. 974). 
Apenas si he retocado algún principio de frase para que las oraciones queden completas, puesto que los pensamientos se encuentran mezclados en los textos de donde he entresacado cuanto me ha parecido de mayor importancia y lo más significativo de la actitud del filósofo.

b) He resumido la Filosofia de la vida artística, a base de los pensamientos y actitudes que juzgo de interés fundamental.

Los diferentes tratamientos de una y otra parte (a y b) obedecen a razones distintas. Me ha parecido que interesa saber con precisión lo que Ramos pensó y expresó en sus ensayos y artículos sueltos, por eso he dado un orden temático a sus pensamientos. En cambio, como él mismo ordenó sus ideas en la Filosofia de la vida artistica, juzgué que en lo fundamental podia resumirse en forma sintética; en todo caso los métodos seguidos concuerdan, de cierta manera, con la realidad del desarrollo del pensamiento estético de Samuel Ramos. Podría también haber llegado a la sistematización total de todos sus escritos, pero he pensado que quizá él mismo se hubiera extrañado, puesto que siempre rehuyó los sistemas y de hecho no produjo una doctrina sistemática.

Ha cle tenerse presente la formación de Ramos. 3 Sabemos que nació a la conciencia filosófica dentro de las ideas positivistas; que pasó por el romanticismo, del que salió por su interés en el pragmatismo y especialmente en su aspecto vitalista. Tal es la herencia recibida de Caso. Vasconcelos le abrió los ojos a las posibilidades de "una interpretación de la cultura Ibero-Americana" y Henríquez Ureña lo introdujo al "neo-realismo sajón". Pero el filosófo más influyente en Ramos fue Ortega y Gasset, menos por el lado del realismo crítico y del neokantismo, mas, sobre todo, por el de las corrientes contemporáneas de la fenomenología, del historicismo, del racio-vitalismo, de la filosofía de la cultura. Estas corrientes fueron la base, a mi parecer, para alcanzar la legítima aspiración de filosofar sobre lo propio y lo relativamente ajeno con acento personal y nacional.

Según han quedado organizados sus Estudios de Estética se advierten de una ojeada sus intereses: "La estética idealista", a base de los conceptos griegos, de la teoría de Kant y de la estética de Croce. Todo

3 Véase el excelente opúsculo de Juan Hernández Luna: Samuel Ramos (su filosofar sobre lo mexicano). México, 1956. (Colección: Filosofia y Letras, núm. 13.) Universidad Nacional Autónoma de México. 
lo expone con claridad y buen estilo y en los momentos oportunos hace su crítica, fundamentalmente para rechazar el idealismo. "La estética contemporánea" 4 se compone con las ideas de Worringer, a quien critica el esquematismo rígido de su teoria sobre "Abstracción y Naturaleza"; " con las de Collingwood, de quien rechaza su idealismo y su subjetivismo radical; con las de Dewey, que expone con entusiasmo porque coincide en lo fundamental, en la experiencia directa del arte como punto de partida de la reflexión; con las de Heidegger, que sabiamente considera para ver lo positivo y las limitaciones del filósofo alemán. En la "Estética de la música" queda, junto a otros ensayos valiosos cuyas ideas generales sirven para todo arte, el ensayo más extenso y mejor trabajado: "El caso Stravinsky", no casualmente de su predilección, pues el clasicismo del músico y sus valores le atrajeron en especial. En la "Estética de la pintura mexicana" también hay un largo ensayo, y el más importante, sobre Diego Rivera," junto a otros de variado interés. Y como en "El caso Stravinsky", en el de Rivera coincide Ramos con el clasicismo del pintor y gusta de los valores estéticos de su obra. Por último, en la "Estética mexicana" expone las ideas de Caso sin omitir discrepancias y los vaivenes de su desarrollo; fue ante todo el sentido metafísico de la estética de Caso que Ramos no pudo admitir. Otro ensayo es el que escribió para prologar mi libro Coatlicue, ${ }^{7}$ en el que me honra al coincidir en ideas fundamentales, sin dejar de señalar mis limitaciones.

Lo anterior no pretende sino servir de gufa al lector en lo que ha de leer a continuación. El orden que he dado a los temas y a los pensamientos incluídos en ellos es cuestionable y digamos que tiene un sentido provisional.

4 En esta sección del volumen en preparación dc "Estudios de Estética" deberân incluirse la exposición y crítica de las ideas de Hartmann, que tan sólo quedaron en conferencias registradas en cinta, pero no escritas.

5 Worringer, W. Abstracción y Naturaleza (Abstraktion und Einfühlung, según el titulo original de la primera edición, 1908). Fondo de Cultura Económica. México-Buenos Aires. (1953. Breviarios, núm. 80. Traducción de Mariana Frenk.)

6 Ramos, Samuel. Diego Rivera. Universidad Nacional Autónoma de México. Dirección General de Publicaciones. 1958. (Colección de Arte, núm. 4.)

7 Fernández, Justino. Coatlicue. Estética del Arte Indigena Antiguo (1* edición, 1954. Centro de Estudios Filosóficos. Prólogo de Samuel Ramos. Ediciones del IV Centenario de la Universidad Nacional, núm. xv). 2* edición, México, 1959. Instituto de Investigaciones Estéticas. Universidad Nacional Autónoma de México. (Colección: "Estudios de Arte y Estética", núm. 3.) 


\section{ESTUDIOS DE ESTETICA}

(Los números al final de cada pensamiento se refieren al orden de los "Estudios de estética", según el indice que se incluye al final de este trabajo.)

\section{Tradición.}

1. Por más alejados que estén nuestro arte y conciencia artística moderna, no podemos excluir a Grecia de nuestras meditaciones.

Hay que descubrir nuestras afinidades y discrepancias.

Hacer un examen crítico, pero no como erudición, ni como curiosidad de historiador. I-2.

2. Platón. Teoría inaplicable a la realidad del Arte, que parece contradecir todas las determinaciones platónicas. 1-1.

El concepto formalista de la belleza de los filósofos griegos, dista mucho de dar una respuesta satisfactoria al problema estético de la esencia de lo bello. I-l.

3. Arte $=$ mímesis, o representación del modelo. sorprende esta concepción tan limitada del arte (estética griega; tema único) . I-2.

4. Plotino parece acercarse más al sentido estético moderno, acaso porque da cabida a lo irracional, anticipación del einfühlung. I-2.

5. Bosanquet - Berkeley - Hogarth - Lord Kames (Henry Home) - Burke. Los filósofos citados creían ingenuamente poder explicar el arte moderno con los conceptos estéticos antiguos (Platón, Aristóteles, Plotino). I-l.

6. Winckelmann, Lessing, quisieron explicar el concepto de lo clásico sobre la base de las teorías estéticas de los propios griegos. I-I.

7. La trascendencia histórica que ha tenido el concepto formalista de la belleza de los filósofos griegos. I-1.

8. Dos posiciones del arte (griegos y modernos); modos diversos de la conciencia artística. No pretendo discutir si una es mejor o peor.

He tratado de comprender la estética griega dentro de su propio ambiente espiritual y evitar juzgarla dentro de puntos de vista modernos. I-2. 
Arte.

9. La obra de arte es una forma especial del "espiritu objetivado". Sorprende que una teorfa filosófica (Collingwood) se ciegue a la evidencia de estos hechos. II-2.

10. Si el arte ha creado un mundo ideal que le es propio, ya por este solo hecho es muy distinto al mundo de la realidad, que es el que la metafísica aspira a conocer como es. V-1. (Contra Caso; arte como conocimiento metafísico.)

11. Me parece que la verdadera conciencia universal del arte debía ser aquella que negara el derecho de dar un privilegio a una forma de belleza, con menoscabo de las otras, y reconociera la existencia de formas múltiples en que las diversas épocas, los diversos pueblos y aun los diversos individuos, han encontrado ese máximo de placer espiritual que va unido a la percepción de lo que llamamos belleza. IV-2.

12. El arte no es pues una mera reproducción de la naturaleza, sino, una creación del hombre que determina la aparición de un mundo que se superpone al mundo natural; resulta improcedente confrontarlo con la realidad. IV-I.

13. La realidad es el documento, la materia prima que el pintor debe transformar en obra de arte. IV-l.

14. El arte no puede darse a ś́ mismo un contenido. Un interés vital es lo que dirige siempre la atención del artista. IV-2.

15. Nos presentan siempre valores relativos, temporales, y que se transforman constantemente. I-1.

16. Lo malo serfa confundir - como los griegos- el arte con la técnica, pero tienen parentesco. I-2.

17. Arte. Una fuerza espiritual influyente en la vida social. I-2.

18. En arte el contenido y la forma no son dos elementos que pueden mezclarse al capricho; prescribe cierta técnica y cierta forma y no otra. IV-2.

19. La voluntad constructiva, el impulso de objetivización, no puede realizarse sin las formas materiales y sensibles que son el lenguaje simbólico del arte. II-2. 
20. El arte es la manifestación de un interés que emana de hondas necesidades vitales del ser, en conexión con la vida. I-4.

21. Sin la vida práctica el arte no existiría. I-4. (Contra el arte por el arte.)

22. El arte grande, inmortal, parece siempre ligado a una tragedia, o cuando menos al sentido trágico de la vida. I-4.

23. La obra de arte es siempre impura. II-2.

24. La discusión sobre si lo que representa el valor estético son los elementos formales del arte o el asunto real que representa es estéril, porque parte del falso supuesto de que en la pintura puede separarse la forma de su contenido real. La obra es percibida como una totalidad. IV-1.

25. No pretendo defender lo que se ha llamado el "purismo" en el arte, indiferente a la naturaleza del tema.

El pintor no puede prescindir del tema, este le sirve como pauta para desarrollar la idea plástica. IV-I.

26. No pretendo describir (obras de Rivera) ni explicar las ideas, porque no creo que este conocimiento sea indispensable para comprender estéticamente sus valores plásticos. En muchos casos la pintura habla por si misma. IV-2. (¿Formalista?)

27. Está demostrado de continuo que el pintor se sirve de los objetos externos no porque sean bellos, sino porque le permiten expresar sus propios estados de ánimo. 1-4. (Contra Croce.)

28. Sin un espíritu universal no se puede ser un gran artista (Rivera), pues el arte representa, a fin de cuentas, la expresión del sentido total de la vida, y ésto le da un sentido humano y social. IV-2.

29. Una cosa es lo nacional y otra lo popular. IV-2.

30. El objeto es incancelable frente al sujeto. I.3. (Contra Kant.)

31. La obra creada tiene un poder limitado; no capta a todos. La capacidad de entrega debe traerla el contemplador. I-3.

Música.

32. La única manera de descubrir la verdadera esencia de la música es partir directamente de la experiencia musical. III-3.

33. La insuficiencia de la filosofía del arte musical se ha debido a que sus autores parten de una metafísica hecha y tratan solamente de encajar en ella los fenómenos musicales. III-s. 
34. No es la naturaleza sino el artista el que impone la ley musical. III-3.

35. El carácter sentimental o emocional de la música, tiene la virtud de abrirnos situaciones espirituales en las que, por así decirlo, se encuentra la totalidad de nuestro ser, todo lo que somos como hombres. III-2.

36. La relación con la vida total es lo que llena de valor a una obra artística. III-3.

37. Clásico=impersonal. Lo importante en el clasicismo es la obra y por amor a ella el artista reprime su interés biográfico. III-3. ,

Critica.

38. La crítica es simplemente la explicación de una obra de arte para facilitar su comprensión. IV-6.

39. La crítica siempre debe adoptar como norma de juicio, la que se deriva de la propia obra que valora. IV-2.

40. El cuadro o la estatua -ahora separados del motivo real quie participó en su origen- debe ser gustado o apreciado por sus propios valores (no por lo que representan). IV-1. (¿Formalista?)

41. Para juzgar acertadamente la obra de arte (Rivera), es preciso llevarla a su terreno propio y estimarla a través de criterios puramente estéticos. IV-2. (¿Formalista?)

42. Crítica $=$ inteligencia $=$ pensamiento. Crítico $=$ artista-filósofo. I-4. Estética.

43. Es evidente que la belleza universal e inmutable, como la belleza pura, por más que satisfagan a la razón y a la lógica, no parecen corresponder a la observación del fenómeno estético.

La belleza no puede ser sino - como lo subraya Justino Fernández- belleza histórica. V-2.

44. Una enseñanza: (de la estética griega) la de que el valor estético "puro" no existe, la de que este valor es siempre "impuro", es decir, que está constitufdo en tal forma que no hace sino polarizar valores de muy diversa especie. I-2.

45. La Estética, en general, es una reflexión filosófica sobre el arte efectivamente creado y producido en la historia de la cultura. III-1. 
46. Toda estética es, primero que nada, la expresión de la conciencia artística de un pueblo, de una cultura. I-2.

47. Lo irracional favorece la comprensión de la esencia del arte. I-2.

48. (Considerar "lo estético" con los hechos de su propio lugar y tiempo: Collingwood.)

Considerar la "circunstancia" =historicismo. Nunca se ha procedido de otro modo, pero ahora se tiene plena conciencia de ello.

La tesis historicista no implica un relativismo absoluto. II-2.

49. Una cuestión de método, a saber, la necesidad de impartir en la meditación del "factum" propio de la estética, qué es la vida concreta del arte. V-1. (Cátedra de Caso.)

50. Una descripción fenomenológica circunscrita al campo de la actividad artística serf́a el medio de proporcionar una visión completa de los procesos que la componen, en toda su continuidad. V-1.

51. Un filósofo que se ocupa de la estética debe poseer un conocimiento de la historia del arte - una experiencia. II-3.

52. La debilidad de muchas doctrinas estéticas es que enfocan los problemas sobre temas abstractos. II-3.

53. Croce tiene sobrada razón cuando no cree en "descubrimientos" estéticos. I-4.

54. Croce aceptaría que la mejor estética es la que más favorece los intereses del arte. Pero ahora los intereses han cambiado. Hemos de ver donde debe colocarse la interrogación más apremiante de la Estética. I-4.

55. Hay que definir cual es el interés propiamente estético en el arte. I-4.

56. Dewey. Su obra tiene un sentido completamente actual. Uno de sus valores radica en que sus ideas son resultados del análisis de las obras de arte. No cae en el vicio de las fórmulas estéticas; es al contrario: un intento de captar la multiplicidad. II-3.

57. Heidegger. Parece un poco extraño que no admita que el arte sea sacado de un círculo metafísico y divino para colocarlo en el círculo de lo humano. II-4. 
58. Heidegger parece borrar el dualismo sujeto-objeto con el empeño tácito pero ilusorio de que la obra de arte habla por sí misma, cuando es el filósofo el que habla por la obra o mejor dicho de la obra. II-4.

59. No se puede tener una comprensión cabal de la percepción o la imaginación si no se toma en cuenta la intencionalidad de la conciencia. II-2.

60. Por más que en todas las doctrinas modernas se encuentren valiosas ideas que han enriquecido el acervo de la estética, casi ninguna de ellas puede lograr nuestra aquiescencia, porque todas pretenden reducir el arte a un elemento exclusivo que empobrece y falsea su complejidad constitutiva. II-3.

61. Creo que la estética contemporánea no tiene más camino para renovar sus conceptos tradicionales que proseguir cada vez más a fondo el análisis fenomenológico de la obra artística. II-4.

FILOSOFIA DE LA VIDA ARTISTICA

No es fácil, ni será posible en esta ocasión exponer la Filosofia de la vida artistica de Ramos en la forma en que debe hacerse pero, a lo menos, es mi intención considerar algunos aspectos que nos aproximen por un momento al espiritu de su autor. Al fin y al cabo lo que cuenta es el pensamiento vivo que revela verdades, o más bien aquello que por coincidencia juzga uno como verdadero y no, como hoy día se estila, atenerse tan sólo a las novedades.

Con buen sentido y cabal intención tituló Ramos su libro: Filosofía de la vida artística, que en sí es revelador de un amplio y variado panorama, en lugar de llamarle, como pudo hacerlo, simplemente: Estética. $\mathrm{Y}$ es que su objeto fue expresar sus ideas, emanadas de su vasta cultura y experiencia, sin pretender hacerlas parte de un sistema, ni de imponerlas como las únicas posibles para los demás, convencido como estaba de que las manifestaciones artísticas son múltiples y heterogéneas y de que "siempre se pueden encontrar aspectos que parecen contradecir cualquier tesis. estética". Desde el inicio encontramos, pues, un espíritu abierto a toda suerte de posibilidades, pero sin que deje de expresar con todo aplomo sus más intimas y personales convicciones. 
Para Ramos el objeto de la estética es el fenómeno del arte observado en ese vasto dominio de la existencia humana que es: la vida artística, que se manifiesta en múltiples formas históricas que hacen problemático encontrar un concepto unitario; así, dice: "lo más prudente es contentarse con la estética particular relativa a un tipo concreto de arte". Esta aparente autolimitación revela desde el primer momento su profunda conciencia del problema, su afán de posible objetividad y concreción y su sinceridad alejada de toda pedantería pseudo cientifica.

Sólo el filósofo con temperamento artístico y con experiencia en el arte puede intentar adentrarse en campo tan especial, su método "debe tender a la investigación de esa función espiritual constante que llamamos artística, para determinar el modo de ser de la obra de arte"; así, no puede prescribir normas estéticas para la creación, ya que su actividad comienza cuando ha terminado la obra el artista. Entonces, poniendo en juego sus posibilidades, ha de guiarlo sobre todo: su intuición.

El objeto artístico debe ser recreado por el sujeto que pretende descubrir sus valores estéticos, por medio de su imaginación y de sus sentimientos, siempre bajo la vigilancia de la inteligencia. Y Ramos denuncia las limitaciones del hedonismo, al que pertenecen, por ejemplo, las diversiones populares. No, la verdadera finalidad del arte es revelar una significación valiosa para la vida y por necesidad tiene que hacerlo a través de formas bellas. Por lo tanto, el contenido y la forma son indivisibles y separarlos conduce a abstracciones parciales de la totalidad del fenómeno artístico. El arte es un lenguaje, un medio de comunicación $\mathrm{y}$, por lo tanto, tiene una función social.

¿Por qué unos hombres de excepción son creadores y otros no lo son? ¿Por qué algunos son genios y otros tienen talento artístico? Tales cuestiones no encuentran contestación; pero el filósofo del arte, el esteta, sí puede observar y distinguir la actividad artística en los diversos aspectos de la vida y en especial en la del artista mismo. Por ejemplo, puede ver que éste oscila entre dos peligrosos extremos: se aproxima a la realidad y llega a la imitación servil, negando de esta manera el arte, o bien se aleja de ella hasta convertir su obra en algo deshumanizado, en cosa muerta y sin sentido. Para Ramos es necesario mantener un punto de equilibrio entre aquellos dos polos $-\mathrm{y}$ en esto se le impone el buen sentido aristotélico-, porque si bien el arte es algo distinto de la vida, no puede existir sin ella. En otros pasajes Ramos se sitúa en posición critica frente a Platón, Aristóteles, Kant y Croce, como cuando 
dice que la ley interna de la obra de arte sólo puede ser descubierta por el análisis critico "a posteriori".

La personalidad artistiça es aquella que se organiza alrededor de un sentimiento estético de la vida y no es ajena a ningún interés humano; el artista con ser él mismo acata, sin saberlo, la voluntad de su tiempo y de su pueblo, mas para realizarse requiere un ambiente de libertad. Y una vez más Ramos se enfrenta a Platón, a Spranger y a Freud, al tratar del amor y del erotismo, pues, dice que el arte trae consigo su propio impulso, que se basta a sí mismo. Considera Ramos otros tipos de personalidades artísticas distintas del creador. El espectador, necesario para entablar el diálogo con el artista y quien interpreta la obra para llegar a intuir los valores estéticos del objeto. El intérprete de la música o de obras teatrales, que tiene un cierto espíritu creador, limitado, porque se le exige la reconstrucción. Y, por último, el crítico propiamente tal, que florece en las fases avanzadas de la cultura y que es exponente de cierta madurez de la conciencia artística general. La crítica presupone experiencia, conocimiento, conciencia vigilante sobre si, juicios objetivos y un concepto estético; su proceso es: la impresión, la reflexión y el análisis, para llegar a pronunciarse por los aspectos estéticos, históricos, sociales y personales de la obra. La vida artística de una sociedad o un pais, dice Ramos, sería incompleta sin la crítica; representa la conciencia de valores que pueden perfeccionarla y engrandecerla.

Ramos considera la independencia e influencia de la obra de arte y su virtud potencial en el espectador entendido. Todo arte es, en cierto sentido, un engaño, una ilusión, pero es también una imagen de la vida; necesita de la transposición del sentido de la realidad, por medio de la metáfora. De esta manera realiza valores y el primero es la belleza, pero sin exclusión de otros fines humanos. Por lo tanto, dice Ramos con todo acierto: "lo que llamamos belleza es en concreto una constelación de valores".

Tales ideas le permiten considerar diversas actividades creadoras y sus sentidos en la poesía, en la música, en las artes plásticas y en la danza, siempre en plan histórico, pues lo que muestran son los diversos ideales de belleza a través de los tiempos, así como una variedad de caracteres propios y específicos; pero, advierte: cuando el arte persigue la realidad se rebaja y si se torna enteramente inverosímil pierde su vitalidad.

En los apartados finales de su obra Ramos resume sus ideas y nos revela el intimo resorte de su posición estética -que es el de toda su 
filosofía. Dice que su lector no habrá encontrado una doctrina conclusa que agote los múltiples aspectos de la estética, pero sí . . . un pensamiento dominante, un espíritu "que ha consistido en evitar toda doctrina rígida o unilateral que fuera inadecuada para abarcar la ilimitada movilidad del arte". Esta amplitud con reservas, esa flexibilidad de la estructura de su pensamiento es la clave para comprender a Samuel Ramos como filósofo por entero, porque tratara este o aquel tema, su ambición fue comprender el complejo de la existencia humana, si bien aceptaba la multiplicidad de sus posibilidades.

Todavia añade algunas ideas que resultan fundamentales. La esencia fenomenológica del arte radica en el movimiento entre la ilusión y la realidad. La función del arte en la vida humana es la de un instrumento de salvación, frente a la negación o insatisfacción de la vida. El arte es la revelación de una vida espiritual; de la realidad transfigurada. $Y$ tiene más poder que una doctrina política, social o moral; su influencia proviene de la fuerza atractiva de su belleza; es un instrumento de educación; es descanso y consuelo; es revelación que no apela a la razón, que crea y recrea al hombre. El arte es para el hombre moderno un remedio para atenuar o curar su angustia metafísica ante la nada. Porque el hombre siempre aspira a rebasar el ámbito de su mera existencia material, ennoblece y alegra la vida con el arte, que constituye una razón de vivir.

\section{CONCLUSIONES}

Si resumimos las corrientes de ideas o actitudes que reflejan los pensamientos estéticos de Samuel Ramos, podemos exponer, ahora con buena base, sus más destacadas caracteristicas (los números que se encontrarán a continuación son referencias al orden que he dado más arriba a los pensamientos) de la manera siguiente.

Respecto del arte y la estética hay un acusado interés por que las ideas y estudios sean absolutamente objetivos (9-32-39-40), es decir que siempre partan o tengan presentes las obras de arte mismas, en un sentido concreto (19-41-49-55-60); actitud que se resume en la necesidad del filósofo-esteta de tener una experiencia. Ramos tuvo un gusto especial, una predilección por el arte clásico, o clasicista -Stravinsky, Rivera- (37), pero en un sentido moderno y profundo, pues por otra parte es anti-naturalista (3-12-13-34). No deja de dar una nota 
afirmativa del sentido trágico (22); hace finas distinciones sobre variados aspectos del arte (16-18-24-25-29-31-38-42); y, no obstante su afán de abarcar siempre la totalidad del fenómeno artístico, en ocasiones parece un formalista (26-40-41). Asl, podemos decir que en materia de arte exigía una experiencia concreta; que tuvo un gusto clasicista en el fondo, pero que su actualidad está presente en su antinaturalismo.

Ramos tiene plena conciencia de la tradición filosófica y artística (1-5-6) y toma posición contra las teorfas metafísicas (10-57) y contra el idealismo, ya sea el clásico, Platón, o el moderno: Kant, Croce, Collingwood (2-23-30-43-44-52-54). Tienen sus escritos notas de espiritualismo (17-35) y de psicologismo (19), pero los caracteres dominantes de su actitud estética son: el vitalismo (1-14-20-21-27-28-36) , por eso admite la función del irracionalismo, desde Plotino (4-47) y el historicismo (8-11-15-43-45-46). Desde estos últimos puntos de vista conviene con la fenomenologia (50-59-61); piensa en una especie de nivelación de los valores (8-11); en las relaciones imprescindibles del arte y la sociedad (17-28); todo como parte de una filosofía de la cultura (45), en la que el interés primordial es el humanismo (45-57-58). Así, algunas de las corrientes del pensamiento contemporáneo le fueron más afines que otras y de todas tomó lo que convino al sentido más profundo de su ser, por eso no juró en absoluto por ninguna, pero su estética puede definirse como ampliamente vitalista, pues su empeño era abarcar la realidad sin limitaciones excesivamente intelectualistas; de aquí su certera definición: "lo que llamamos belleza es en concreto una constelación de valores". Mas hay que agregar que pensaba en valores históricos, circunstanciales. Su originalidad consiste en la modulación personal que supo dar a las direcciones del pensamiento contemporáneo para expresar sus más intimas convicciones filosóficas y estéticas. Contradicciones las tiene como todos los que no somos dioses.

Todo lo anterior queda incluido y bien expresado en su Filosofia de la vida artistica. A todo aquél cuyos intereses coincidan de algún modo con el arte y la estética, la lectura de la obra de Ramos le despejará muchos problemas y le enriquecerá el espíritu, pues en la actualidad resulta una guía de primer orden en aquellos campos. Por mí puedo decir que no sólo la lectura de sus obras sino la amistad con que me distinguió el maestro amplió mis conocimientos y mi espiritu; nuestras coincidencias son múltiples. Su trato gentil y bondadoso ocultaba un alma grande y generosa. 
Samuel Ramos fue un filósofo, un humanista, un esteta y un mexicano excepcional; su lugar está entre los que han sabido elevarse a lo universal sin perder sus propias ralces, antes al contrario nutriéndose de: ellas; entre los que han creado una obra de valor positivo y de influencia permanente en la cultura.

Samuel Ramos: ESTUDIOS DE ESTETICA.

(INDICE del volumen en preparación)

I. LA ESTETICA IDEALISTA.

1. El concepto griego de lo bello.

2. La estética griega.

3. La teoría de Kant sobre el placer estético.

4. La estética de Benedetto Croce.

ii. LA ESTETICA CONTEMPORANEA.

1. La estética de $G$. Worringer.

2. La estética de R. G. Collingwood.

3. La estética de John Dewey.

4. La estética de Martín Heidegger.

5. Los valores estéticos de Nicolai Hartmann.

III. ESTETICA DE LA MUSICA.

1. Estética de la música en los filósofos románticos.

2. La música y el sentimiento.

3. El caso Stravinsky.

IV. ESTETICA DE LA PINTURA MEXICANA.

1. Estética de la pintura.

2. Diego Rivera.

3. Veinte años de pintura en México.

4. Julio Castellanos.

5. Santiago Rebull.

6. Manuel Iturbide. Pintor y aguafortista.

V. ESTETICA MEXICANA.

1. La estética de Antonio Caso.

2. La estética del arte indígena antiguo de Justino Fernández.

3. Estética de la Ciudad de México. 


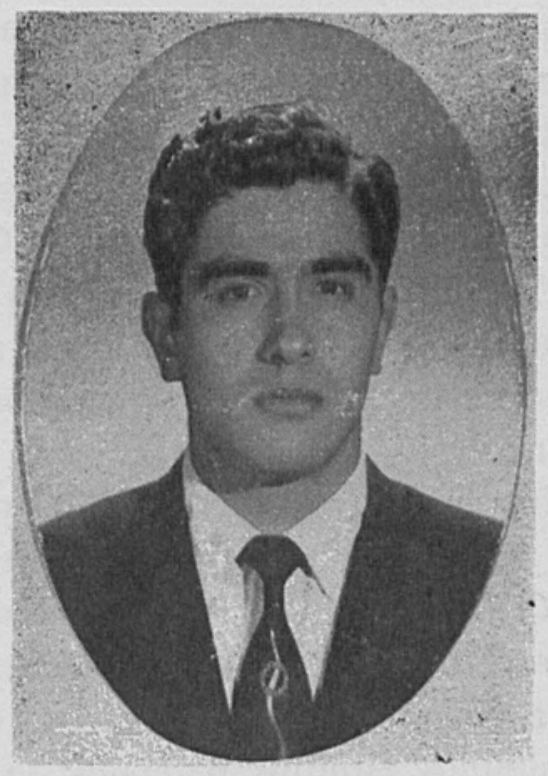

\section{RAUL FLORES GUERRERO (1930-1960)}

Las primeras líneas de este número de Anales han sido en recuerdo de un maestro recientemente fallecido y ahora, ya en prensa esta revista, nos vemos obligados a insertar aquí otra noticia similar: nuestro compañero Raúl Flores Guerrero murió, en Nueva York, el día 8 de mayo del presente año.

Nació en México el 19 de febrero de 1930 y en esta ciudad hizo sus estudios, que culminaron en dos carreras: la de Arquitectura, de la que cursó tres años, y la de Historia, especialización en Arte, que concluyó. Durante los últimos cinco años sirvió diversas cátedras de historia del arte, en la Universidad Nacional de México y en algunas otras instituciones, y desde 1953 lo tuvimos entre nosotros, como 
investigador de nuestro Instituto. El año pasado de 1959 obtuvo una beca del Institute of International Education y pasó a ampliar sus estudios en la Universidad de Columbia, en Nueva York, a la vez que iniciaba un trabajo sobre la escultura contemporánea por encargo del Instituto de Investigaciones Estéticas.

Historiador y crítico de arte, sensible e inteligente, lo revelan sus numerosos artículos en estos Anales, en México y la Cultura (suplemento dominical del diario "Novedades", de esta ciudad) y en otras muchas publicaciones. Cuando se revisen sus opiniones se estimará más su valor como crítico, uno de los más tinos y fecundos que hemos tenido, no obstante su juventud.

Varias obras tenía, en diversas fases de preparación, cuando lo sorprendió la muerte: una reseña crítica de Los murales de la Ciudad Universitaria y un Compendio del Arte Prehispánico de México, el plan de compilar, revisar y completar una serie de ensayos sobre el barroco popular mexicano, tema muy importante que ya inicialmente había acometiclo en algunos estudios parciales; la investigación sobre escultura contemporánea, ya antes aludida; tal vez otros proyectos más, ya definitivamente frustrados.

Por todos motivos: por su labor truncada, por el futuro que en él había como investigador y estudioso de nuestro arte, por el comprñero y amigo que en él tuvimos, la muerte de Raúl Flores Guerrero es una dolorosa pérdida que ha sufridlo el Instituto de Investigaciones Estéticas. 